STELla MARIS Fernández. Delibrosybiblidteras, Buenos Aires, Sociedad de Investigaciones Bibliotecológicas, 2000. 186p.

Reseña elaborada por:

\title{
ADOLFO RODRÍGUEZ GALLARDO
}

Tste libro contiene una serie de trabajos que han sido publicados tanto en Argentina como en otros países de América Latina. Tal es el caso de "El libro y sus mundos en la antigüedad", publicado en el Boletín de la Biblioteca General de la Universidad del Zulia, Dirección de Cultura de Maracaibo, pero por un error tipográfico el apellido de la autora fue cambiado a Hernández en lugar de Fernández. Además se incluye otro trabajo publicado previamente como es "Muerte y resurrección del Libro" editado anteriormente en 1977 por el Instituto Bibliotecológico de la Universidad de Buenos Aires.

Acerca de los trabajos "Los libros pintados mejicanos", "El libro de Kells y sus interrogantes", "Silvio Eneas Piccolomin (Pio II y la Biblioteca del Duomo de Siena", y "Las muy ricas horas del Duque de Berry", no se indica si son nuevos o han sido publicados con anterioridad.

En el prólogo se indica que "Los periódicos de la gesta de mayo; sus redactores y la Imprenta de Gandarrillas" es inédito. 
Como se observa por los títulos de los trabajos, éstos cubren una amplia gama de temas tanto argentinos como de otros lugares, tal es el caso de la colaboración sobre los libros mexicanos o bien el que trata sobre la Biblioteca de Siena.

Stella Maris Fernández es una impulsora decidida de los trabajos de investigación en la Argentina, ha dirigido el Centro de Investigaciones Bibliotecológicas de la Facultad de Filosofía y Letras de la Universidad de Buenos Aires. Al dejar el cargo de directora de ese Instituto en 1998, fundó junto con un grupo de renombrados bibliotecarios y con la colaboración de un grupo entusiasta de jóvenes bibliotecarios argentinos, la Sociedad de Investigaciones Bibliotecológicas, que es una sociedad privada sin fines de lucro y que es la editora de este libro. Además la Sociedad ha publicado otros seis libros y dos números de su revista anual Infodiversidad.

Los trabajos presentados son sin lugar a dudas un conjunto de aportaciones al conocimiento de los temas que aborda.

En el primero nos presenta un conjunto de reflexiones sobre el origen de la escritura y la lectura en la antigüedad, en el que recurre a una serie de autores clásicos para armar su estudio. Las fuentes citadas nos indican que la autora ha hecho una revisión exhaustiva de los autores clásicos para analizar temas como la lectura y la escritura y otros más, como, la lectura pública y el plagio.

El segundo trabajo está dedicado al estudio de los libros pintados mexicanos y analiza diferentes aspectos como por ejemplo: los materiales utilizados, la preparación del papel, quiénes los hicieron, el valor histórico de esos materiales, la clasificación y el formato de los libros, y finalmente describe algunos de los códices que se encuentran en diferentes bibliotecas del mundo.

El trabajo sobre "El libro de Kells" es una descripción de esta valiosa obra que se encuentra en la biblioteca del Trinity College de Dublín, Irlanda. Contiene los evangelios y está bellamente ilustrado; la autora nos ofrece un análisis del libro y un estudio histórico que nos permite conocer las vicisitudes que ha pasado el libro el que nos llega con mutilaciones y daños irreparables. No obstante el daño recibido el libro sigue siendo una obra de arte que vale la pena estudiar y conocer.

En el trabajo sobre Pío II la autora nos ofrece una relación de los datos más importantes de este personaje y posteriormente hace una selección de pasajes de su autobiografía. Pasa posteriormente a describir la biblioteca del Duomo que fue contenida por Pío III, sobrino de Pío II, y termina su trabajo con una relación de los hechos más importantes de la vida de Pío II.

Las muy ricas horas del Duque de Berry" es un trabajo que aborda las características de este tipo de materiales bibliográficos, tanto en sus rasgos físicos como en el contenido de estos materiales; se trata de una revisión histórica que cubre con profundidad el tema y que en especial nos ofrece un análisis de la obra "Las muy ricas horas.

Un detallado estudio hemerográfico es el que nos ofrece la autora en su trabajo intitulado "Los periódicos de la gesta de mayo, sus redactores y la imprenta de Gandarillas". Esta última fue la segunda imprenta que se estableció en Buenos Aires y en 
este trabajo se encuentra detallada su actividad, así como las personas que colaboraron en ella,

Muerte y resurrección del Libro" fue publicado por el Instituto Bibliotecológico de la Universidad de Buenos Aires en 1977 y se agotó rápidamente. Tiene como propósito poner en evidencia la preocupación y el esfuerzo que el hombre ha realizado y viene realizando desde la aparición del libro -aun en sus primeros formatos- hasta la época actual, a fin de salvarlo de la destrucción que los agentes naturales, el tiempo, los insectos y el hombre mismo provocan.

Es este un volumen muy interesante que muestra la profundidad del trabajo de la autora y la variedad de temas que aborda, no obstante lo cual en todos los trabajos se advierte un conocimiento profundo del tema acompañado de una muy rica documentación que apoya el trabajo realizado.

Es éste un libro que muestra el rigor del trabajo de la autora, cabe desear que la Sociedad de Investigaciones Bibliotecológicas siga por el camino emprendido 